\title{
Situational Approach of Leadership - Case Study at "Kujtesa" Company
}

\author{
Adelina Arifi ${ }^{1}$, Musa Krasniqi ${ }^{2} \&$ Berim Ramosaj $^{3}$ \\ ${ }^{1}$ University of Pristina"Hasan Prishtina", Faculty of Economics, Kosovo \\ Correspondence: Adelina Arifi, University of Pristina"Hasan Prishtina", Faculty of Economics, Kosovo. E-mail: \\ adelina.arifi@student.uni-pr.edu
}

Received: September 20, 2021; Accepted: October 8, 2021; Published: October 11, 2021

\begin{abstract}
In the contemporary time in which we live, the approach of leaders plays an important role in implementing the strategy of the "Kujtesa" company. The purpose of this research is to show the application of leadership style to their subordinates. The methodology used in the study is a combination of quantitative and qualitative data. The results of the research were processed with the data of 100 employees and managers of the "Kujtesa" company. The data were processed using the statistical analysis of SPSS program. This research includes the analysis of key factors of leaders' style with their subordinates such as: human resource management, work structure, management readiness to face new challenges and new situations. This study shows a clear picture of the functioning of leaders' approaches to subordinates.
\end{abstract}

Keywords: leaders, leadership, human resources, situational approach, subordinates

\section{Introduction}

A simple definition defines leadership as the art of motivating a group of people to act towards achieving a common goal. In a business environment, this can entail leading employees and colleagues with a strategy to meet the needs of the company.

This definition of leadership captures the essence of being able to inspire others and being prepared to do so. Effective leadership is based on ideas (whether original or borrowed), but it might not happen if those ideas cannot be communicated to others in a way that engages them sufficiently to act as the leader wants them to act.

The leader is offered a series of approaches, both traditional and contemporary. Over the years, leadership approaches have evolved and are becoming more sophisticated in many respects such as; in improving working methods, in the role of collaborators. The situational approach is part of contingent leadership approaches. It is oriented towards subordinates, is characterized by adaptability and flexibility and as such is considered as a successful approach to leadership. According to the situational approach, the effective leader is the one who changes the leadership style depending on the situations. This paper aims to understand whether the situational approach is applied and how effective it is for the leadership at "Kujtesa" company.

\section{Purpose of the Study}

Given that Kosovar society is still undergoing transition, in economic and socio-cultural terms, it is thus difficult for Kosovar business organizations to be identified with a concrete leadership model and approach to organizational success. Without neglecting leadership behavior, which as treated in the literature review, autocratic leaders basing their work on fear of punishment and reward, tended to clone followers according to their own interests. But, can this kind of leadership style bring organizational effectiveness to the distribution of cable networks?

The purpose of this paper is to find leaders of different styles who work in the same company, have similar tasks but different jobs or positions, and to distinguish between them in terms of success, results achieved in relation to others and work in general.

The leadership approaches are: Psycho-dynamic, team approach, transformative approach, leader-follower exchange, path-goal, contingent, institutional leadership, leadership-based approach and behaviors, approach based on the totality of skills and experiences, approach based on personal characteristics or traits. While the main focus of this paper is the situational approach, on what this approach is based, how much it is used and how 
effective it is at "Kujtesa" company. The situational leadership approach states that the leader acts differently in different contexts, implying that the leadership style should be adapted across situations.

\section{Research Methodology and Design}

\subsection{Research Methodology}

The following research methods have been used to comprehensively study the problem in question:

Data sources: There were used two types of data sources: primary and secondary. In the first part of this paper, data were collected from secondary sources, such as: literature of various authors, articles and various publications in scientific journals. This collected data has served to, through the method of description and analysis, review and draw conclusions about the leadership approach, how much it is used and how effective it is at "Kujtesa" company.

Research methods: the surveying method is used as a research method with 100 questionnaires.

Data processing is based on the use of various statistical methods such as: methods of analysis, descriptive method - through which the results obtained from the answers of the questionnaire were described, and bivariate correlation analysis.

The selection of literature review includes the study of books, articles, papers of national and international journals and conferences, etc. For the concepts of this paper, a series of articles from different researches were used, making a selection of them in advance. The selected reference sources also helped to outline the content and the necessary concepts that were included in the paper to prove the theories.

Also, the selection of literature is spread over a relatively considerable number of authors, taking into account the complex nature of the retrospective issue regarding the leadership approach, how much it is used and how effective it is at "Kujtesa" company.

There were used tabular, graphic and video presentation methods to present the findings.

Research sample included 100 respondents.

Contact technique: the direct/onsite contact technique has been applied to collect the data.

Data analysis and processing - A questionnaire was used to collect the data, data processing was done in the application of the Statistical Package for Social Sciences (SPSS), through which, various tables were extracted and various statistical tests were applied, such as the correlation coefficient through which showed the strength of the correlation between the variables of study.

Hypothesis 1: The leadership approach plays an important role in decision - making.

Hypothesis 2: Adapting the style to the situation affects the improvement of the final results and the implementation of the strategy.

\section{Literature Review}

The issue of the leader and his/her influence on business organizations and mainly in society, for many decades, has been the subject of study by many researchers. Some of them came to the conclusion that leaders are born that way (Carlyle, 1993), while many others claim that they are made during life. The saying of the great playwright William Shakespeare: "Some are born great, some become or achieve greatness." Today's view in general is that all men and women can become leaders, regardless of their gender (Feldman-Summers and Kiesler, 1974), age (Mezulis et al., 2004), and ethnicity (Morris and Peng, 1994). It is enough to avoid the obstacles of their personal background and the limitations of the environment that surrounds them (Allio, 2009). But regardless of whether leaders are born or made in life, whether male or female, at least it is certain that organizations of all sizes engage in a competitive environment. They more than ever need effective leaders who understand the complexity of the ever-evolving global environment; have the intelligence, sensitivity, and ability to motivate their followers to strive for excellence (Amagoh, 2009).

According to Burns (1978), "Leadership is one of the most observed and least understood phenomena in the world" (Burns, 1978), but the vast number of research and studies on leadership conducted in recent decades has provided us with a better approach to the history of leadership models, their impact on society, and moreover a more positive and complete perception of what makes an effective leader (Eagly, et al., 2003; Eagly, 2007; Holt etc., 2009; Jogulu, 2010). It is worth mentioning that leadership models have evolved and expanded through years.

Moreover, about five decades before, Bass and Avolio (1994) and Weber (1947) would focus on leaders divided into three groups according to their styles in search of success. $\bullet$ bureaucratic style; $\bullet$ charismatic style, and $\bullet$ traditional style. In his approach, Weber also believed that leaders pursued two basic personalities, transactional 
and transformative. Teaching the theory that the bureaucratic leader was a transactional leader and charismatic leaders were transformative leaders, both Bass and Avolio (1994) considered transformational and transactional leadership styles as distinct but not mutually exclusive. They acknowledged that the same leader could use both types of leadership styles in different times and situations, such as unpredictable reward is an effective leadership style, but just not as effective when used with transformative factors (Roper, 2009). According to the behaviors of transactional and transformational leadership Bass (1985), influence and inspirational leadership appear when the leader envisions a desirable future and clearly expresses how this can be achieved by setting high standards of performance and determination in meeting the goal. The main concepts of the leadership study is the art or process of influencing people in order to orient their efforts towards achieving the objectives of the organization (Llaci, 2010). Transformational leadership is the leader who inspires the success of the organization profoundly influencing followers' belief in what an organization should look like (Bass and Avolio, 1994). Whereas, transactional leadership is the leader who uses the mechanism of control and rewards to motivate one's subordinates externally (Bass and Avolio, 1994). Laisez-Faire leadership is the type of leader that in itself is oriented towards the absence or avoidance of leadership. Moreover, Laissez-Faire leaders do not make decisions, delay actions, ignore responsibilities, do not use any kind of power, and avoid getting involved (Bass and Riggio, 2006). Organizational culture, according to Schein (1985), is a model of common ground assumptions that the group has learned after solving its external adaptation and internal integration problems that have functioned well enough to be considered valid and consequently, to teach new members the right way to perceive, think and feel about such problems" (Schein, 1985). Adaptability, the degree to which an organization has the ability to change behavior, structures, and systems in order to survive.

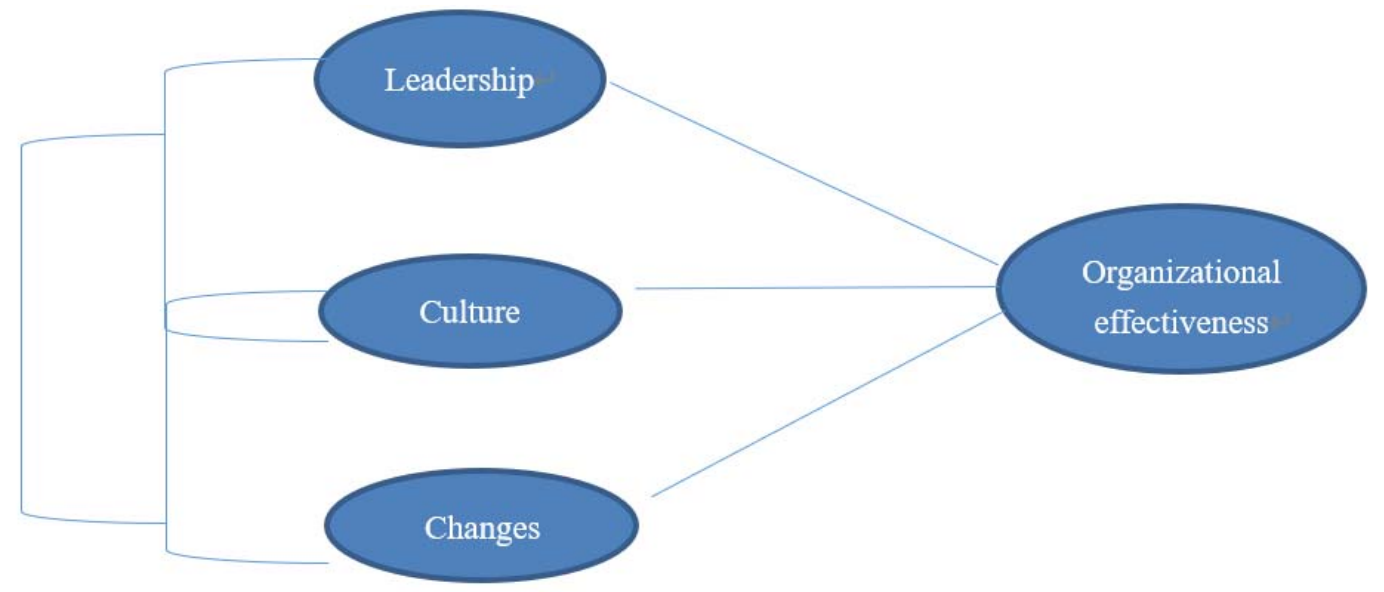

Figure 1. Conceptual model

According to Gandhi, once upon a time leadership meant 'muscles', but today leadership means getting along well with people. Emphasizing the relationship between the leader and subordinates, as a key point of leadership, the leadership ability is to determine a person's level of efficiency. The lower an individual's ability to lead, the lower the peak of his potential. The higher an individual's ability to lead, the higher the peak of his potential. (Maxwell.C.John), "Leadership usually transforms potential into reality. Knowing closely, motivating and assigning tasks which should be in line with the capacity and skills of subordinates. Leadership will also be defined as the integration of character, knowledge, skill and desire. Character is your being. Knowledge is the theoretical paradigm of what should be done and why. Skillfulness is how you serve, how it will be done. And, the desire is the motivation, the desire to do." (Canco Galantina; Donika Kërçini; Zegali Lidra; Ciroka Ndriçim; "Organizational Behavior", Tirana, 2012, p.245) "Leadership is the ability to get great performance from ordinary people." Another definition is: "Leadership is the ability to get followers." The more successful the achievement of objectives, the more visible and effective the leadership.

\subsection{Situational Approach}

The situational approach is known as one of the most popular approaches in leadership. It was created by Dr. Paul Hersey, professor and author of "Situational Leader" and Ken Blanchard, author of "One-Minute Manager". In 1969, Blanchard and Hersey developed the leadership situation theory in their classic book, "Organizational Behavior Management", which is based on Reddin's theory of "3D Management Style". During the mid-1970s, this theory was renamed into the situational leadership theory. This theory was introduced about ten years after 
Fiedler theory and similarly focuses on tasks and relationships but varies in important areas. As the name of the approach suggests, situational leadership focuses on organizational leadership. The concept of this theory is that different situations condition different styles of leadership (Northouse, G. Peter, "Leadership: theory and practice", Michingan, 2013, p. 99). First, Paul Hersey and Kenneth Blanchard assume that leaders are more flexible than Fiedler considers them. They argue that leaders need to change behavior as followers' maturity increases. This is the first situation theory that addresses the element of maturity of followers/employees. Maturity is defined as "the capacity to set high but achievable goals (achievement-motivation), the willingness and ability to take responsibility, the education and development of an individual or group" (Hersey, Blanchard, 1976). In general, leadership means choosing the right leadership style for the right people.

\section{Research Findings}

In this paper, a practical research was conducted through the direct surveying technique, where the managers of the "Kujtesa" company were surveyed.

The "Kujtesa" company was founded in 1995, initially as a Computer Hardware Retailer and later became an Internet Service Provider.

In 2006, "Kujtesa" entered the cable television market in Kosovo. Today, the Kujtesa TV platform contains over 160 channels, including the KSport channel platform. Kujtesa offers high quality solutions for the Kosovo market in the fields of internet, digital television and fixed telephony. "We are always in step with the innovations of world technology, and the first to implement them in Kosovo". The "Kujtesa" Company has a total of 300 employees in the following departments: Marketing, Sales and Telesales, Call center, Customer Service and Ceo. A total of 100 managers employed in Kosovo participated in the questionnaire. It is committed to providing services for the needs of businesses and families, and offers them reasonably priced choices that accurately match their requirements. The company offers customers services that make their lifestyle, work, learning and entertainment experience more advanced.

The first question has to do with the age of the respondents (managers), where the age groups are divided into these categories: 18-35 years old, 36-65 years old and over 65 years old as in the following table:

\begin{tabular}{lll}
\hline Answer alternatives & No. of answers in $\%$ & No. of answers \\
\hline $18-36$ years & $26 \%$ & 23 \\
$36-65$ years & $72 \%$ & 72 \\
Over 65 years & $1 \%$ & 2 \\
Total of respondents & $100 \%$ & 100 \\
\hline
\end{tabular}

Figure 2. Graphic presentation of the age of the respondents

The table above shows that the largest number of respondents includes the 36-65 age category with $72 \%$, followed by the second age group $18-36$ years old with $26 \%$, and over 65 years old with $1 \%$. As for the age over 65 , they are retired, but due to their expertise at work, the term of employment has been extended.

2. How are the decisions made in your company?

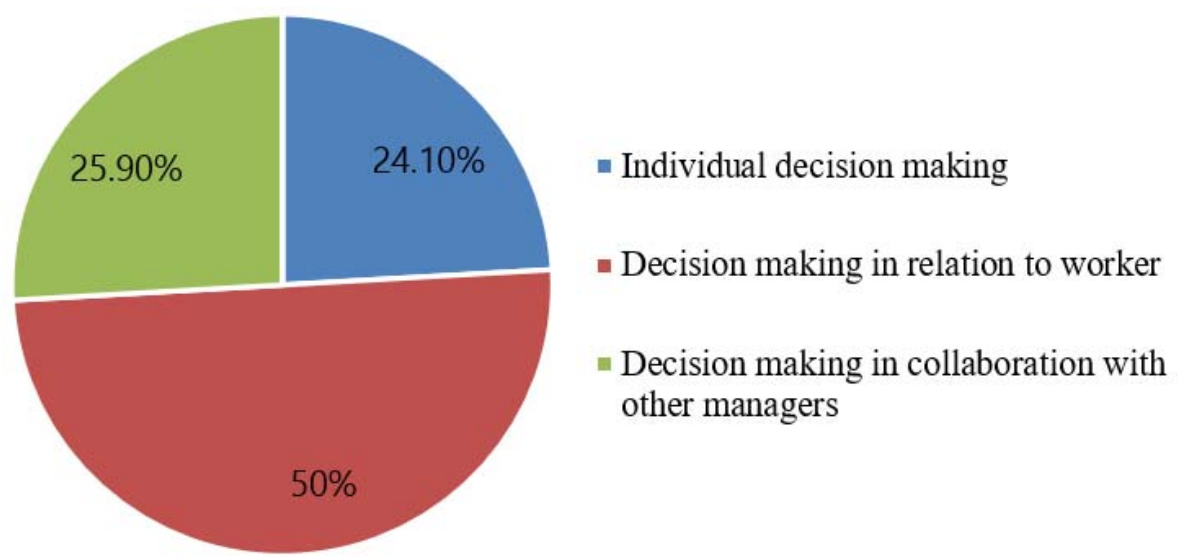

Figure 3. Graphic presentation related to company decision - making 
Decision-making is accomplished when choosing the alternative from a range of available alternatives. $50 \%$ of respondents stated that they make decisions in cooperation with employees in the organization. $25.90 \%$ of respondents stated that they make decisions in cooperation with other managers, in most cases they make decisions with the board of directors. While they use individual decision-making in more complex situations, where at first they discuss with the board of directors or with the employees, but the final decision is made by them individually. $24.10 \%$ of respondents indicated that they apply individual decision-making. As a result, the majority of decisions are made on an individual basis.

3. Based on decision-making experiences, which decision-making is more effective individual or in groups?

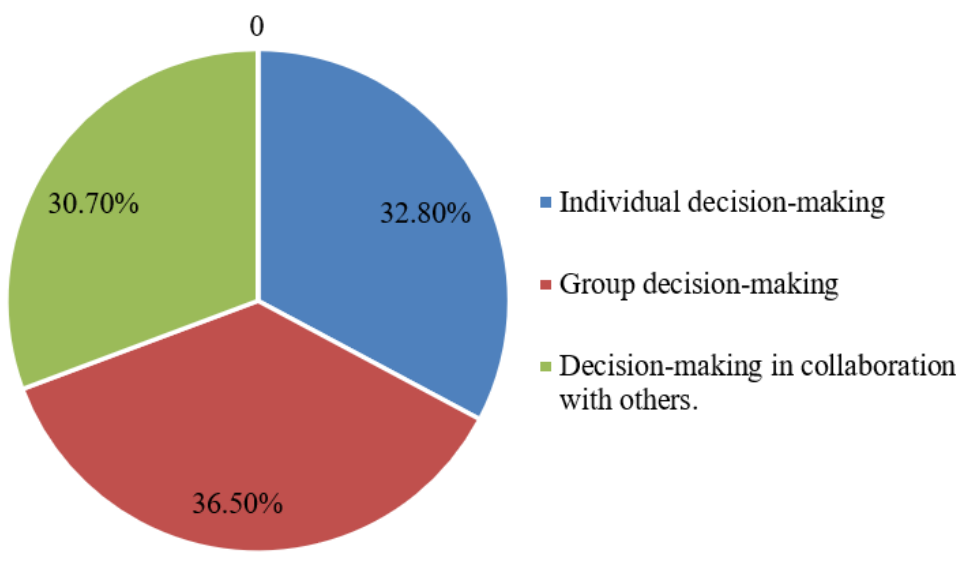

Figure 4. Graphic presentation on effective decision-making

In the next question, $32.80 \%$ of respondents answered for individual decision-making and 36.50 percent for group decision-making. From responses on decision-making in collaboration with other managers are $30.70 \%$.

Individual decision-making according to managers is very effective when faced with strategic decisions as they have experience, preparation and adequate development. They said that there are times when they trust personal intuition more than the opinions or facts offered by others. This form of decision-making is less costly than the group one and does not take much time.

The group decision-making that managers use as the most effective and productive in their work highlighted that the more members involved in choosing strategic alternatives the lower the likelihood of avoiding any significant dimension.

4. Are your employees present in the decision-making process in every situation?

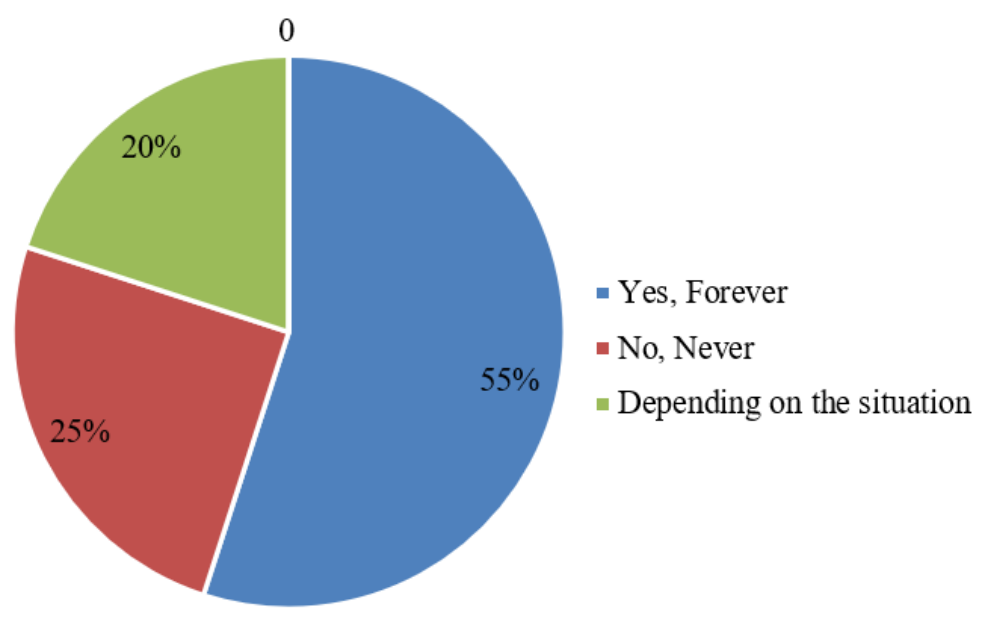

Figure 5. Graphic presentation regarding the presence of employees in the decision-making process 
The following are the results of the question about the presence of employees in the decision-making process:: 55 percent of leaders take the opinion of employees in decision-making, 25 percent never, and 20 percent depending on the situation and then together choose the best alternative.

5. Is the capacity and readiness of employees considered when you have new changes and develop new projects in your company?

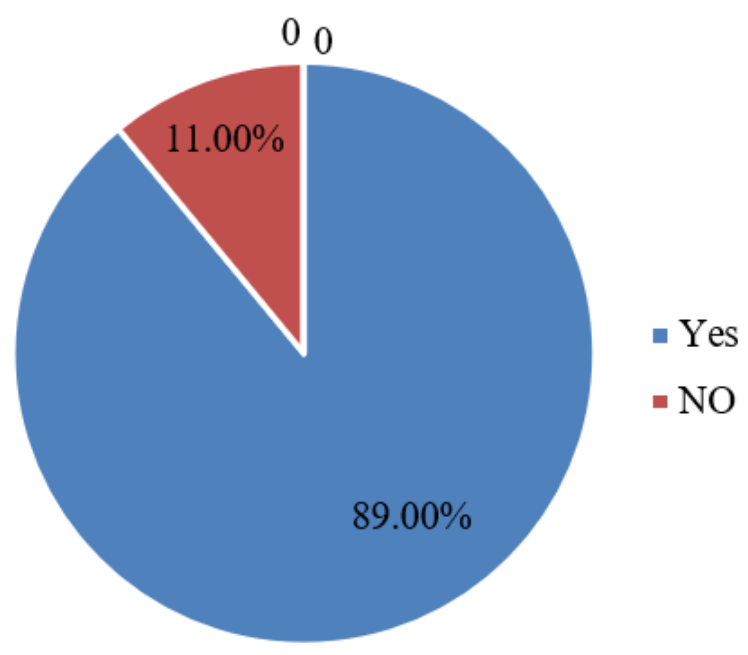

Figure 6. Capacity and readiness of employees

To the next question whether the capacity and readiness of employees is considered when undertaking changes in the work process or when developing new projects, do you take into account the capacity and readiness of workers, $89 \%$ of respondents answered that they are taking it into account, while $11 \%$ answered that they do not consider the capacity and willingness of employees when making decisions.

The leaders who answered positively to this question said that, when they make changes in the work process or when developing new projects, they first look at whether these changes are adapted to the organization's objectives, time, conditions available and especially human resources.

6. When dealing with complex situations how do you manage your employees?

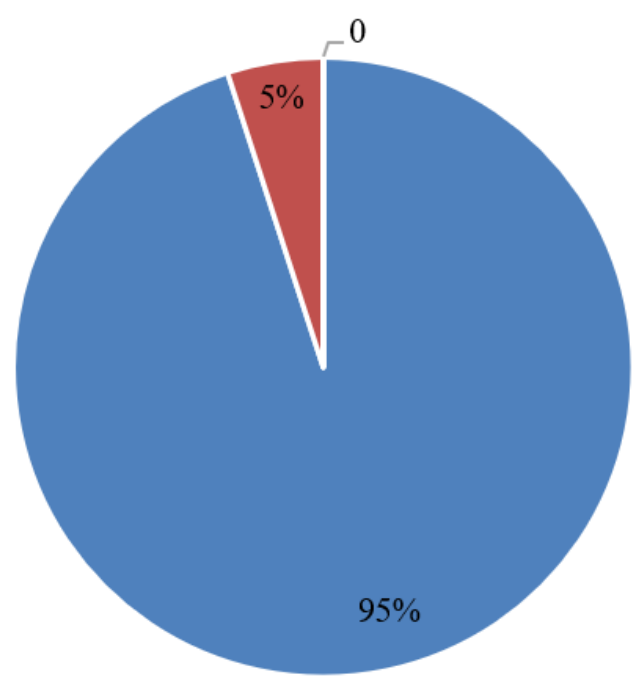

- order their employees to achieve certain objectives

- Motivate for the achievment of objectives

Figure 7. Graphic representation related to employees management in complex situations 
All respondents expressed that they face complex situations during their work. They stated that $95 \%$ in complex situations order their employees to achieve certain objectives. Only $5 \%$ lead employees in complex situations through motivation.

7. How do your employees adapt to new situations?

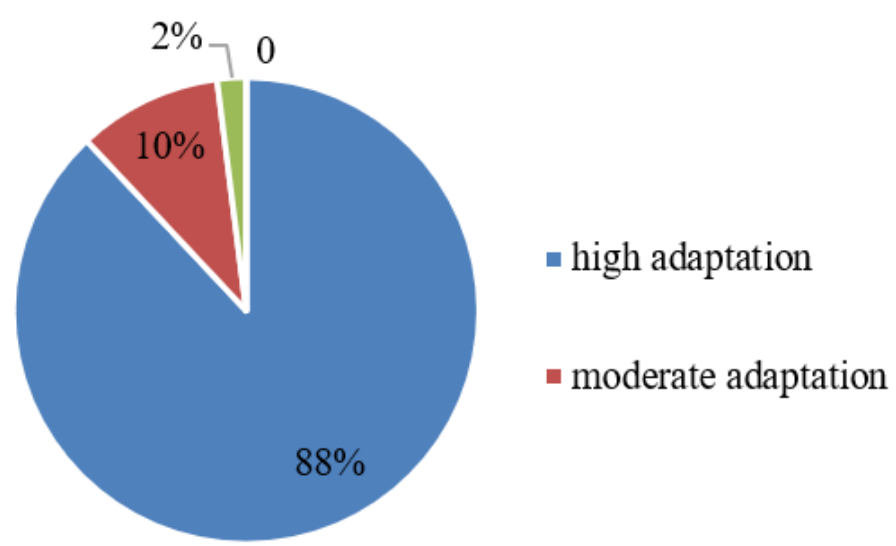

Figure 8. Adaptability of employees in new situations.

When asked how employees adapt to new situations, they answered that $88 \%$ of employees have high adaptation, $10 \%$ have moderate adaptation and $2 \%$ have low adaptation. Organizations routinely deal with new situations and it is more than normal to notice both positive and negative changes. Most leaders say they have mostly young staff and are very enthusiastic, creative and innovative to accomplish tasks, and they easily adapt to new changes.

8 . How ready are your employees to complete new tasks with high efficiency?

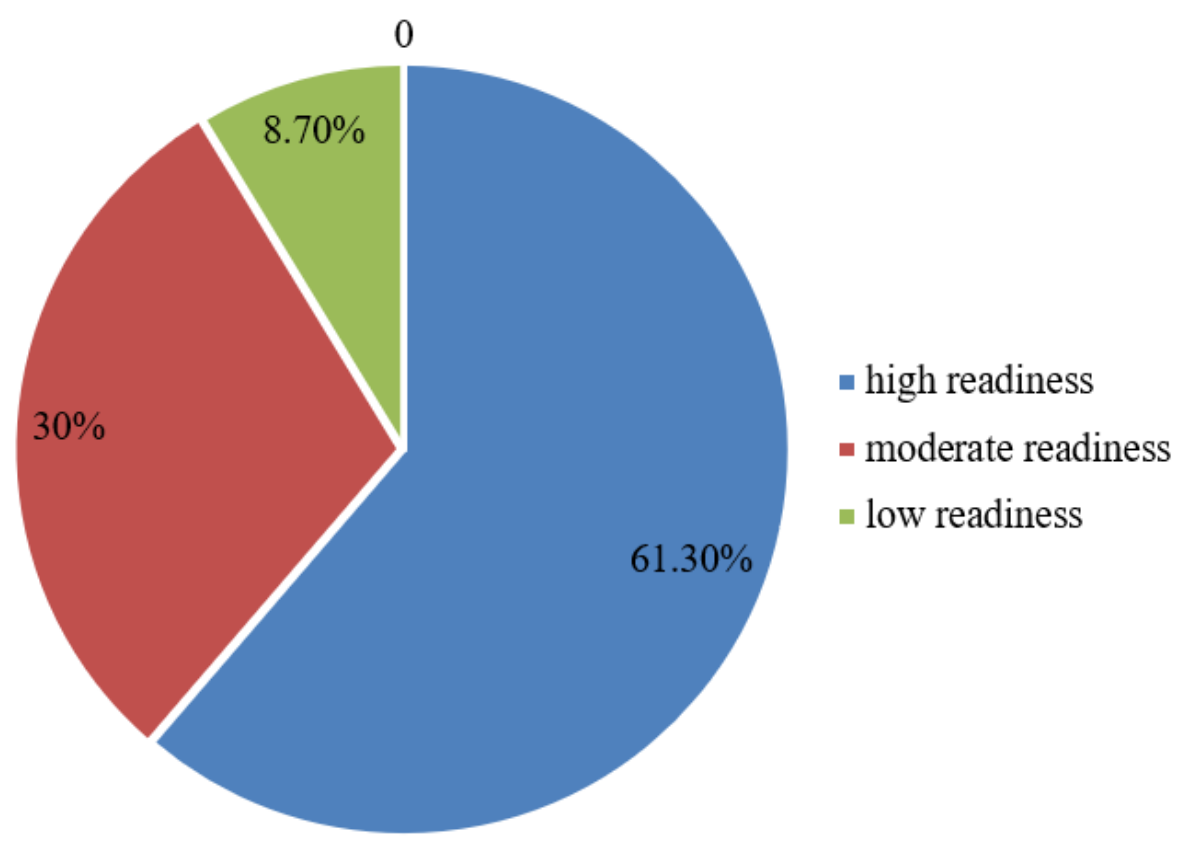

Figure 9. Willingness of employees to complete tasks

In this question the respondents with $61.30 \%$ had high readiness to complete new tasks, $30 \%$ moderate readiness and 8.70 low readiness. But leaders in such cases act through assistance, monitoring, consultation, mutual cooperation while avoiding setbacks.

9. Are situational factors analyzed during the work process? 


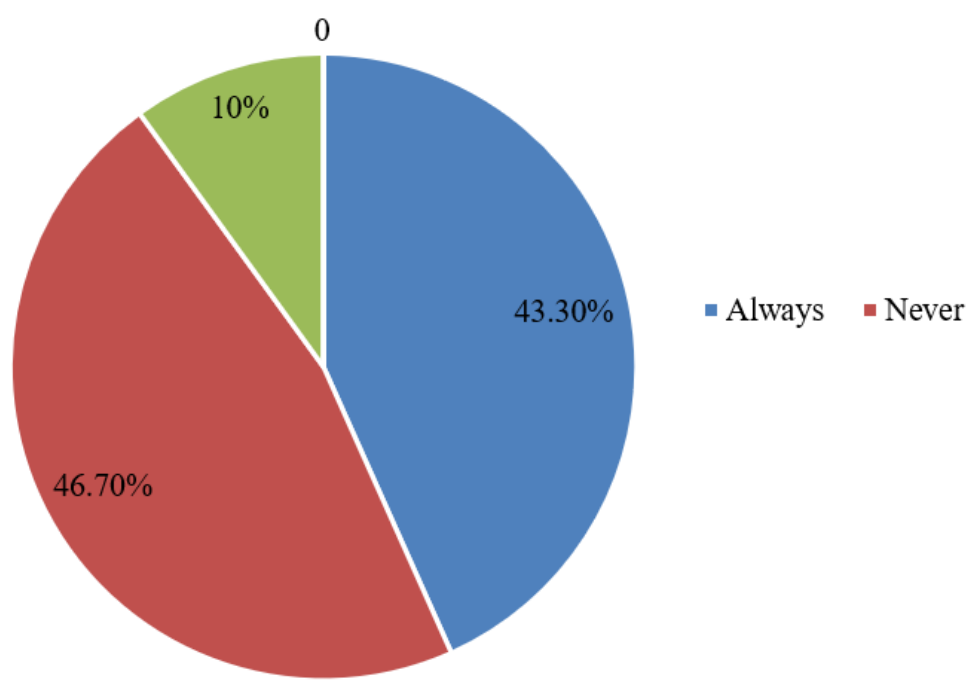

Figure 10. Graphic presentation related to the analysis of situational factors

To the question "Do you as a leader analyze situational factors", $43.30 \%$ of respondents always analyze the situational factors, while $46.70 \%$ of them sometimes depending on the situation and only $10 \%$ of them never analyze the situational factors. For the leaders who answered to use these factors in their work process, the choice was justified because they constantly analyze the factors of the situation, as they want to be prepared and not cause imbalance depending on the situations they faced. The second group with $46.70 \%$ answered that they sometimes analyze the situational as they review the basis of the situation as they see fit or needs. The rest responded that they do not take them into account as they usually act more spontaneously.

10. Do you invest in human capital (training-development)?

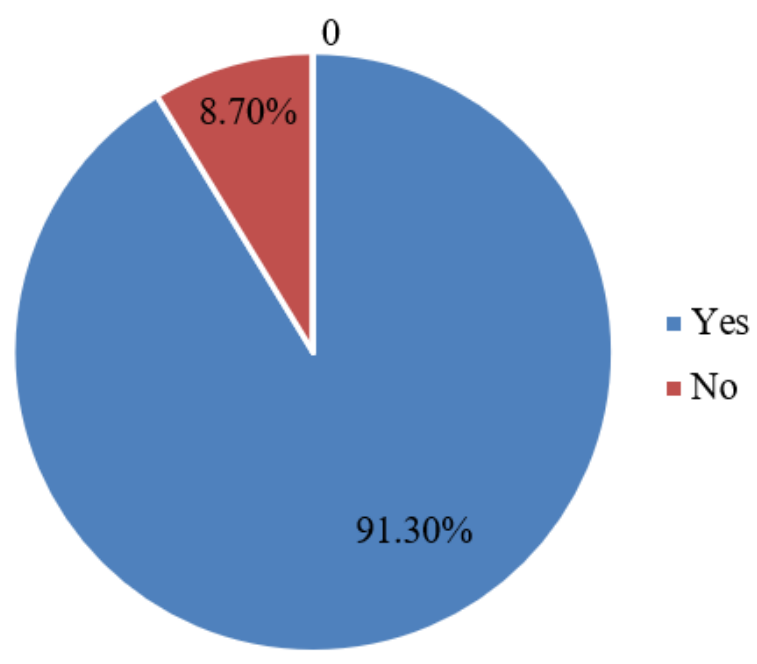

Figure 11. Graphic presentation related to human capital investments

Organizational performance is closely related to staff empowerment, professional freedom and participation in training and experience. Most respondents seem to be fully informed about the role and importance of training for human resource development, training plan, job objectives, are subject to annual staff appraisal and assess the importance of minimum employment criteria. $91.30 \%$ answered that they invest in human capital, while $8.70 \%$ do not invest. 


\subsection{Multivariable Regression Analysis}

In statistical modeling, the regression analysis is a statistical process for evaluating the correlation between variables. The regression involves many techniques for modeling and analyzing several variables, when the focus is on the correlation between a dependent variable and one or more independent variables. More specifically, regression analysis helps to understand how the typical value of the dependent variable changes when one of the independent variables has changed, while the other independent variables remain the same. In linear regression, the dependent variable is denoted by " $y$ " while the independent variables are denoted by " $x$ ", which in our case are the same variables that are analyzed and commented on the correlation coefficient. The independent variables " $\mathrm{x}$ " are: $\mathrm{x} 1$ - the impact of the situational approach on the success of the company $\mathrm{x} 2$ - The degree of improvement of the final results " $y$ " y proximity and cooperation of leaders with subordinates.

The following table shows the multivariate regression analysis.

Tabela 5. Multivariable regression analysis

\begin{tabular}{|c|c|c|c|c|}
\hline Model s & & & & \\
\hline Model & $\mathrm{R}$ & R Square & Adjusted R Square & \\
\hline 1 & $.779^{\mathrm{a}}$ & .685 & & .407 \\
\hline
\end{tabular}

Predictors: (Constant) the influence of leadership style, the adaptation of the style to the situation affects the improvement of the final results.

$\mathrm{R}$ represents the multivariate correlation coefficient that shows the correlation between the independent variables with the dependent variable, $\mathrm{R}=.779$ at this level $\mathrm{R}$ indicates that there is a strong positive correlation between the variables.

$R$ squared $\left(R^{2}\right)$ represents the percentage of the dependent variable that can be explained by the independent variables - is the coefficient of determination or coefficient of determination $\mathrm{R} 2=.685$, indicates that the independent variables " $\mathrm{x}$ " can interpret $68.5 \%$ of the variability in the variable dependent " $y$ ", which in this case is the cooperation of leaders with subordinates.

Adjusted $\mathrm{R}$ Square adjusts the value of $\mathrm{R}^{2}$ when the sample size is small, because an estimate of $\mathrm{R}^{2}$ is obtained when the sample size tends to be higher than the actual $\mathrm{R}^{2}$. According to the "rule of thumb" - the rule of thumb or acceptance is reported to adjust $\mathrm{R}^{2}$, when it differs substantially from $\mathrm{R}^{2}$ (Green \& Salkind, 2010). In this analysis the difference is relatively small Ajdusted $\mathrm{R}^{2}=.685$ therefore can be reported $\mathrm{R}^{2}$; and the standard error calculated is 0.407 .

The following table presents the statistical test table of the analysis of variance known as ANOVA.

Table 5.1 Results from the statistical test of variance analysis - ANOVA

\begin{tabular}{|c|c|c|c|c|c|c|}
\hline \multicolumn{7}{|c|}{ ANOVA $^{\mathrm{a}}$} \\
\hline Model & & $\begin{array}{l}\text { Sum of } \\
\text { Squares }\end{array}$ & df & Mean Square & $\mathrm{F}$ & Sig. \\
\hline \multirow{3}{*}{1} & Regression & 11.071 & 5 & 2.2142 & 15.072 & $.000^{\mathrm{b}}$ \\
\hline & Residual & 13.636 & 94 & .145 & & \\
\hline & Total & 23.640 & 99 & & & \\
\hline
\end{tabular}

Predictors: (Constant) the influence of leadership style, the adaptation of the style to the situation affects the improvement of the final results.

Regression, Residual, dhe Total are the categories which will be discussed.

Sum of Squares links to three sources of the Total, Model and Residual variable. The Total variance is divided into variance that can be explained by independent regression variables and variables that are not explained by independent Residual variables.

df (degree of freedom) - these are the degrees of freedom that are related to the sources of variants. The total variance is $\mathrm{N}-1$ of the degree of freedom. The regression rates of freedom correspond to the number of estimated coefficients minus 1 . Thus out of 8 coefficients, the model has 6-1 $=5$ degrees of freedom. Total DF minus model DF, $99-5=94$. 
Mean Square - these are Sum of Squares divided by their respective DFs: 11071/5 =2.2142, 13.636 / $94=.145 .06$.

F dhe Sig. - This is F statistic and p value associated with it. F-statistic is Mean Square (Regression) divided by Mean Square (Residual): $\mathrm{F}=2.2142 / .145 .06=15.072$. And $\mathrm{p}$ is $0 \mathrm{p}<0.00$. The data that came out as a result of the SPSS table labeled as ANOVA gives the results of a test of significance of $\mathrm{R}$ and $\mathrm{R}^{2}$ using F-statistics. In this analysis, the value of $p$ is below $.05(p<0.00)$. Therefore, we can conclude that $R$ and $R^{2}$ are statistically significant (all independent variables $\mathrm{x}$ have a significant relationship with the dependent variable $\mathrm{y}$ ). The following table presents the test of independent variables to verify whether there is statistical significance between variables. The table also presents the t-test results, which enables us to confirm or refute the hypotheses from $\mathrm{H} 1$ to $\mathrm{H} 2$.

Table 5.2 Statistical significance of independent variables

\begin{tabular}{|c|c|c|c|c|c|}
\hline Coeffic & & & & & \\
\hline Model & $\begin{array}{l}\text { Unsta } \\
\text { Coeff }\end{array}$ & & $\begin{array}{l}\text { Stand } \\
\text { Coeff }\end{array}$ & & Sig. \\
\hline & $\mathrm{B}$ & Std. Error & Beta & & \\
\hline (Consta & & & & & \\
\hline $\begin{array}{l}\text { The inf } \\
\text { importa } \\
\text { approac }\end{array}$ & g.294 & .045 & .597 & 6.481 & .000 \\
\hline $\begin{array}{l}\text { Adaptin } \\
\text { the imp } \\
\text { the imp }\end{array}$ & $\begin{array}{l}s \\
d-155\end{array}$ & .062 & -.267 & -.2 .490 & .015 \\
\hline
\end{tabular}

B - These are the values for the regression equation to predict the impact of the dependent variables on the independent variable. The regression equation is presented as follows:

$Y=b 0+b 1 * x 1+b 2 * x 2$

Beta $\beta$ - Standardized coefficients. These are the standardized coefficients of all regression variables, including the dependent variable and all independent variables. We will also notice that the beta coefficients that are larger are associated with the largest t-values and the lowest p-values.

$t$ and Sig. - These are the $t$-statistics and their p-values that test whether the given coefficient is significant. The significance is between the alpha rating level from 0 to 0.05 . Based on the results from the table above, we can see that the hypothesis:

H1: "Leadership approach plays an important role in decision - making", it is validated because the value of significance required by the standard is less than $p<0.05$, while in our case, it is seen that the significance value of the variable is related to leadership approach is $p=0.00$. which corresponds to the required standards $p<0.05$. While the value of the Beta coefficient is $\beta=.592$ indicates that there is a strong average ratio between these two variables.

From the findings we see that this has helped to create a more suitable working environment, which has then helped to achieve the increase in speed in decision - making. Most leaders say they practice participatory and group decision-making. They adapt the leader style according to the situations but also according to the maturity levels of the subordinates.

H2 - "Adapting the style to the situation affects the improvement of the final results and the implementation of the strategy" - this is true, and the value of the Beta coefficient is $\beta=.-267$, the negative value coefficient indicates i $\beta$ that there is an inverse ratio between the variables.

Based on the empirical results, this hypothesis is confirmed by the responses of the managers who were involved in the research and where the approach of the leaders has had a positive impact on the relations between the employees. The hypothesis is accepted based on these answers indicating that the situational approach is closely correlated to effective leadership.

At the "Kujtesa" company, the situational approach has shown to be a viable approach to effective leadership. The conclusions were drawn from the questionnaire's empirical analysis. Situational leadership advises that the proper leadership style be chosen for the right people at the right time. The adaptability of this approach, as well as the situational factors, are its defining characteristics. All of these areas were included in the questionnaire in order to gain a sense of how effective this method is for the "Kujtesa" company. The findings of the study demonstrate that 
organizational leaders utilize a situational approach and pay close attention to personnel and their abilities to complete allotted duties.

\section{Recommendations and Conclusion}

Following the findings and analysis, the recommendations that should be considered in future leader positioning are to boost productivity and enable its management inside the company, as well as to increase employee motivation for work.

Another recommendation is to promote participation and engagement. Anyone who takes on a leadership role should be committed to the organization of the group. The group's vision and objective should be internal to the leader. An effective leader is someone who can devote to guiding people, performing technical skills, and anticipating scenarios or situations in order to reach the goal.

As a result, we recommend three key characteristics of organizational culture be considered in order to ensure that it has a positive impact on organizational effectiveness: First, it must be worthwhile by contributing to the productive activities. Second, the organizational culture must be distinct or unique, with traits and values that allow for value diversity and competitiveness within the organization or company. Third, culture cannot be perfectly imitated by other organizations, although while a manager may aspire to create a favored and flawless culture, it is impossible to achieve due to the multiple hidden or visible aspects that contribute to it.

As shown in the above sections of the study, leadership itself has a significant impact on organizational effectiveness, so any organization is required to implement the most effective leadership practices in order to have a successful competition in the market. The data emerged from the study show that situational leadership has a greater impact compared to other approaches to leadership. Therefore, it is important that at the managerial level this leadership model takes on greater importance for this sector as long as it guarantees higher organizational effectiveness compared to other models. Based on the final findings, it is recommended that the managers of "Kujtesa" should approach the transformational leadership style that is most effective in the work environment and employee management while also appreciating the maturity of the employees.

This leadership style should inform employees of what is to be done and why, give a realistic picture of the organization's vision, and serve as the impetus to achieve the ultimate goal of the organization. Subordinates who have excellent leadership are rewarded with long-term careers that are founded on a positive relationship between managers and subordinates, which has a direct impact on organizational effectiveness. Affinity and cooperation with subordinates make leaders more successful and more acceptable to subordinates.

In conclusion, creative leadership promotes the development of work and creative environments. The company said that "Kujtesa" has a relatively young staff, so in order to get the best out of them, steps should be taken to avoid routine work, and staff should be constantly trained. Therefore, it is very important that employees are developed personally and professionally in the field within the job. Finally, the communication between leaders and employees should be the key pillar for effective leadership.

\section{References}

Abrahamson, E. ( 2000). Change Without Pain. Harvard Business Review, 78(4JulyAugust): 75-79.

Alas, R., Tafel, K., \& Tuulik, K. (2007). Leadership style during transition in society: case of Estonia. Problems and Perspectives in Management, 5(1), 50-60.

Alderfer, C. P. (1969). An empirical test of a new theory of human needs. Organizational Behavior and Human Performance, May, 142-75. https://doi.org/10.1016/0030-5073(69)90004-X

Aldrich, H., \& Ruef, M. (2006). Organizations Evolving, 2nd ed., Sage, Thousand Oaks, CA. Allen, S. and Hartman, N. (2008). Leadership development: an exploration of sources of learning.

Allio, R. J. (2005). Leadership development: Teaching versus learning. Management Decision, 43(7/8), 1071-7. https://doi.org/10.1108/00251740510610071

Andrews, J., Cameron, H., \& Harris, M. (2008). All change? Managers"experience of organizational change in theory and practice". Journal of Organizational Change Management, 21(3), 300-314. https://doi.org/10.1108/09534810810874796

Antonakis, J., Cianciolo, A. T., \& Sternberg, R. J. (2004). Leadership: past, present, and future. Advanced Management Journal, 73(1), 10-62.

Barney, J. B. (1986). Organizational culture: Can it be a source of sustained competitive advantage? Academy of Management Review, 11, 656-665. https://doi.org/10.5465/amr.1986.4306261 
Bass, B. M. (1998). Transformational Leadership: Industrial, Military and Educational Impact". Lawrence Erlbaum, Mahwah, NJ.

Beck , D . E., \& Cowan, C. C. (1996). Spiral Dynamics: Mastering Values , Leadership , and Change , Blackwell Publishers, Oxford.

Becker, T . E., Billings , R, S., Eveleth , D. M., \& Gilbert, N . L. (1996). Foci and biases of employee commitment: implications for job performance. Academy of Management Journal, 39(2), 464-482. https://doi.org/10.2307/256788

Berry, L. L., \& Parasuraman, A. (1992). Prescriptions for a service quality revolution in https://doi.org/10.1016/0090-2616(92)90071-T

Bhatnagar, D. (2007). Strategic HRM-A Tool To Leverage Organizational Effectiveness. Journal of IPM, Meerut , $8(2)$.

Bonne, E. L., \& Kurtz, L. D. (2011). Contemporary Business. United States of America.

Caldwell, C., \& Dixon, R. (2010). Love, forgiveness and trust: critical values of the modern leader. Journal of Business Ethics, 93, 91-101. https://doi.org/10.1007/s10551-009-0184-z

Canco, G., Kërçini, D., Zegali L., \& Ciroka N. (2012). Organizational behavior, Tirana, albania.

Cangemi, J., Burga, W., Lazarus, H., Miller, R., \& Fitzgerald, J. (2008). The real work of the leader: a focus on the human side of the equation. Journal of Management Development, 27(10), 1026-1036. https://doi.org/10.1108/02621710810916286

Dvir, T., Eden, D., Avolio, B. J., \& Shamir, B. (2002). Impact of transformational leadership on follower development and performance: a field experiment. Academy of Management Journal, 45(4), 735-744. https://doi.org/10.5465/3069307

Egner, T. (2009). Behavioral Leadership- The managerial Grid. Germany.

Fiedler, F. E., \& Chemers, M. M. (1984). Improving leadership effectiveness: The leader match concept (2nd ed.). New York.:Wiley.

Gordon, J. (2003). The Pfeiffer Book of Successful Leadership Development Tools. San Francisco, USA.

Hofstede, G., \& Peterson, M. (2000). Culture: National values and organizational practices. In N. Ashkanasy, C. Wilderom, \& M. Peterson (Eds.), Handbook of organizational culture and climate (pp. 401-416). Thousand Oaks, CA: Sage.

Jansson, N. (2013). Organizational change as practice: a critical analysis. Journal of Organizational Change Management, 26(6), 1003-1019. https://doi.org/10.1108/JOCM-09-2012-0152

Koli, Z. Shyqyri, Sh. (2005). Human Resources Management. Tirana, Albania.

Kotter, P. J. (2008). Force For Change: How Leadership Differs from Management. New York, USA.

Maxwell C. J. (2007). The 21 Irrefutable Laws of Leadership Workbook: Revised and Updated. United State of America.

McCauley, D. C., \& Velsor, V. E. (2004). The Center for Creative Leadership Handbook of Leadership Development. San Francisco.

McIntyre, R. M., Jordan, P., Mergen, C., Hamill, L., \& Jacobs, T. O. (1993). The Construct Validity of the CPA: Report on Three Investigations. Alexandria, VA: U. S.Army Research Institute for the Behavioral and Social Sciences.

Mehrotra, A. (2005). Leadership styles of Principals. New Delhi.

Northouse, G. P. (2013). Leadership: theory and practice. Michingan.

Pride, W., Hughes, R., \& Kapoor, J. (2009). Business. USA.

Puccio, J. G., Mance, M., \& Murdock, C. M. (2011). Creative Leadership: Skills That Drive Change. United states of America.

Ramosaj, B. (2007). Management - Basics of management. Pristina.

Ramosaj, B. (2012). Management - Creative management with leadership. Pristina, 2012.

Tracy, B. (2013). Delegation and supervision. New York. 


\section{Copyrights}

Copyright for this article is retained by the author(s), with first publication rights granted to the journal.

This is an open-access article distributed under the terms and conditions of the Creative Commons Attribution license (http://creativecommons.org/licenses/by/4.0/). 